\title{
Absence from work after the birth of the first child and mothers' retirement incomes: A comparative analysis of ten European countries ${ }^{1}$
}

Running head: Absence from work after the birth of the first child and mothers' retirement incomes

\begin{abstract}
This article investigates whether a prolonged absence from the workforce after the birth of the first child is associated with mothers having a lower retirement income and whether cross-national variations in family policy and pension systems moderate the relationship between work interruptions and retirement incomes in ten European countries. The analysis, based on five waves of SHARE data, indicates that the longer a mother abstains from work after the birth of her first child, the lower her retirement income is. However, the association is negligible in countries where mothers are historically supported by a comprehensive welfare system, namely Denmark, Sweden and the Netherlands. The findings indicate that generous work-family reconciliation policies and universally oriented pensions system are the most effective in minimising longterm motherhood income penalties when they are jointly present, pointing to the importance of policy packages that combine active and passive measures to achieve dual decommodification.
\end{abstract}

Keywords: family policy, gender gap, motherhood penalty, pension systems, retirement income, SHARE.

Giulia M. Dotti Sani², University of Milano Statale

Matteo Luppi, INAPP, National Institute of Public Policy Analysis

${ }^{1}$ Published in Work Employment \& Society (2020), Online first. https://doi.org/10.1177/0950017020937935

${ }^{2}$ Corresponding author: Via Conservatorio 7, 20122, Milano, giulia.dottisani@unimi.it 


\section{Introduction}

Much previous research has studied differences in incomes and earnings between childless women and men, mothers and fathers, and women and their partners (Klesment and Van Bavel, 2017; Stier and Mandel, 2009). Empirical evidence on the topic in western countries is univocal: mothers have lower earnings than childless women (Budig and Hodges, 2010; Gangl and Ziefle, 2009), experience more job interruptions (Jefferson, 2009), have lower pensions (Folbre et al., 2007) and face a greater risk of poverty in old age compared to men (Gornick et al., 2009; Peeters and De Tavernier, 2015). However, the extent to which motherhood engenders long-term income penalties and whether they vary cross-nationally has not been fully studied: cross-national research on the topic seldom focuses on mothers in their later years and international comparisons are mostly confined to a few countries (Fasang et al., 2013; Ginn, 2003; Phipps et al., 2001; SigleRushton and Waldfogel, 2007). In contrast, this article uses data from ten European countries with different welfare systems to test whether the length of absence from the labour market after the birth of a first child is associated with mothers' retirement incomes at age 60 and above and how, if at all, family policies, childcare availability and pension systems mitigate the relationship between years out of the labour market and retirement income. The article also analyses mothers' incomes relative to that of their partners with the aim of providing a comprehensive account of both within- and between-gender differences in income in later life.

Achieving a clear understanding of long-term income inequalities among mothers is relevant both theoretically and from a policy perspective. Theoretically, this article provides a contribution by complementing and extending the existing literature on motherhood penalties. This field of study generally focuses on the short- or at best medium-term consequences of motherhood on employment and income (Boeckmann et al., 2015; Budig and Hodges, 2010; Dotti Sani, 2015; Lalive and Zweimüller, 2009; Sefton et al., 2011; Uunk et al., 2005), leaving us with a critical question unanswered: are there very long-term consequences of job interruptions on mothers' retirement incomes? In this respect, our study informs current theoretical debates by highlighting the long-lasting nature of motherhood penalties and showing that mothers' child-related work interruptions are associated with losses in earnings that go well beyond the short term. In terms of policy, our comparative perspective sheds light on the most effective combination of policy measures to minimise long-term motherhood income penalties through a dual decommodification policy strategy that combines both active and passive labour market protection measures. Ultimately, the cross-national differences 
that emerge in the study point to a need to rethink how post-maternity absences from work affect mothers' incomes in the long run from a comparative standpoint, thus pushing forward both theoretical and policyoriented thinking about what still needs to be done to mitigate gender inequalities at the intersection of work and family life.

The analyses are based on data from the Survey of Health, Ageing and Retirement in Europe (SHARE), rounds two (2006-7), four (2011-12), five (2013) and six (2015) combined with the retrospective wave of the survey (round three, 2008-2009) for ten European countries with a good variety of different types of welfare and pension systems: Austria, Belgium, Denmark, France, Germany, Greece, Italy, the Netherlands, Spain and Sweden. The findings show that the longer mothers abstain from work after the birth of their first child, the greater the losses are that they will experience in terms of retirement income after age 60 , both in absolute terms and relative to their current partner. However, no association emerges between absence from the labour market and retirement income in northern European countries and in the Netherlands, where mothers are supported by a comprehensive welfare system. Crucially, neither a highly redistributive pension system nor a generous maternity package, taken separately, can shelter mothers from severe losses in retirement income: mothers fare economically better in countries such as Sweden, Denmark and the Netherlands where both types of measures are in place, i.e. where they are directly or indirectly favoured in their working trajectory but are also guaranteed a pension as citizens and not only as workers.

\section{Absence from the labour market and mothers' long-term incomes}

Previous studies show that women have lower pensions than men in many western countries (Burkevica et al., 2015; Fasang et al., 2013; Peeters and De Tavernier, 2015; Sefton et al., 2011) and that women in later life are especially vulnerable to poverty risks (Gornick et al., 2009; Peeters and De Tavernier, 2015). In the light of the gender differences in unpaid domestic work and childrearing (Treas and Drobnič 2010), work interruptions due to maternal responsibilities may be responsible for long-term gender differences in income in older segments of the population (Mincer and Ofek, 1982; Sigle-Rushton and Waldfogel, 2007). Long work interruptions reduce labour market attachment (Lalive and Zweimüller, 2009) and limit wages (Baum, 2002; Ejrnæs and Kunze, 2013; Phipps et al., 2001) and the chances of career progression, all of which decrease income in later life. However, most research on the topic focuses on the short-term effects of job interruptions 
on mothers' labour market behaviour (Boeckmann et al., 2015; Lalive and Zweimüller, 2009; Uunk et al., 2005) and subsequent earnings (Budig and Hodges, 2010; Sefton et al., 2011), whereas few cross-national studies test the long-lasting effects of childbirth and child-related work interruptions on women's retirement incomes. Moreover, to our knowledge no comparative empirical evidence exists on the association between mothers' absence from work after the birth of their first child and their retirement income relative to their partners, i.e. mothers' share of the couple's total retirement income. While studying mothers' absolute income in relation to the length of their child-related work interruptions can provide important policy indications to limit within gender income inequalities, looking at income inequalities between mothers and their partners provides insights into between gender income inequalities, and consequently into crucial yet understudied issues of power and dependency between women and men in older segments of the population. Therefore, to draw a comprehensive picture of gender inequalities in income in older age in a comparative perspective, it is relevant to go beyond women's personal incomes and focus on whether long child-related work interruptions interact with institutional features in shaping mothers' shares of household income later in life.

Previous studies point in the expected direction. Recently, a study by Möhring (2018) has looked at whether motherhood and the number of children affects the retirement incomes of women aged 60 to 75 in 13 countries using SHARE data. Her results reveal that fewer years in employment and lower status jobs are in large part responsible for mothers' lower retirement incomes, and that institutional factors such as redistributive pension systems can mitigate gender differences in income in later life. Despite focusing on an important long-lasting cause of gender inequality in later life, i.e. the number of children, the study does not explicitly model absence from work due to maternal responsibilities. Sigle-Rushton and Waldfogel (2007) show that mothers in eight industrialised countries have lower earnings than childless women and men, and that the effects of childbearing are long-lasting, but their sample is limited to subjects up to 45 years old. Similarly, Kahn et al. (2014) use US data to show that motherhood has negative consequences on women's labour force participation, occupational status and wages for women up to the age of 50. Comparable results have been found for Canada (Phipps et al., 2001). In contrast, research shows that men tend to increase their work effort and income when they become fathers (Killewald, 2013), therefore ameliorating their current income situation and laying the ground for their long-term economic security. Based on this reasoning, the first hypothesis tested in our study is that the longer a mother abstains from work after the birth of the first child, the lower her absolute and relative 
retirement income will be in later life $(\mathrm{H} 1)$. When considering important structural and cultural differences in the countries under consideration, which will be discussed in the following section, cross-national differences in the association between absence from work and retirement income are expected.

\section{The role of family policies and pension systems}

Previous studies underline the fundamental role of national institutional features in shaping women's labour market behaviour around childbirth (Pettit and Hook, 2005; Stier et al., 2001). In this article, three areas of welfare are considered: 1) maternity leave regulations; 2) childcare availability; 3) pension systems. We focus on these three policy areas because we aim to understand the decommodification role of the welfare state, namely, its ability to support women's economic welfare regardless of their family roles and labour market participation. Social policies of this type constitute the primary drivers of decommodification. However, labour market policies (LMPs) can also support this process. Indeed, "in-work decommodification" (Pintelon, 2012) is crucial in "lessening individuals' dependency on the pure cash nexus" (Esping-Andersen, 2000: 358). Therefore, while our reasoning is mainly linked to the traditional forms of decommodification, in the discussion section we integrate our results by looking at how LMPs can condition women's labour market behaviour around childbirth.

\section{Maternity leave}

In most of the countries considered in this article, maternity leave was provided for as early as the $1960 \mathrm{~s}$ (Gauthier, 2011). In 1960, Austria granted 12 weeks of maternity leave at 100\% of the previous pay, and the number of weeks grew to 16 in 1974. Germany has also traditionally offered new mothers generous protection, with $100 \%$ pay for 12 weeks until the 1970s and later for 14 weeks. Similarly, new Dutch mothers could rely on 12 weeks at $100 \%$ from 1960, which were increased to 16 in the 1990s. In 1960, France granted 14 weeks at $50 \%$ pay, which became $90 \%$ in 1970 . Both the length and the pay increased over the years, reaching 16 weeks of leave at 100\% from 1997. Maternity pay in Denmark was set at 19\% for 14 weeks in 1960 but rapidly grew to $90 \%$ for 18 weeks in the 1980s. In Sweden, new mothers were initially relatively well protected, with 26 weeks of leave remunerated at nearly $70 \%$ in 1969. Maternity leave was abolished in the 1970s and replaced with a more comprehensive package of parental and childcare leaves that included fathers, allowing new mothers a prolonged period at home with relatively high pay. 
Other countries provide a somewhat less comprehensive coverage of maternity interruptions. In Belgium, a maternity leave scheme was introduced in 1958 with 12 weeks covered at $60 \%$, which was gradually increased to 15 weeks covered at about $77 \%$ in the late 1990s. In Spain, maternity leave was 12 weeks at $60 \%$ in 1960 and increased in the following years to 16 weeks at $100 \%$. Greece has one of the least generous schemes, with maternity pay of 50\% from 1960 to 2010 . Only the number of weeks has increased, from 12 to 17. Italy also fails to fully compensate its new mothers, with maternity pay at $80 \%$ for a relatively long period of 21 weeks.

\section{Childcare}

Empirical studies suggest that public childcare or childcare subsidies support the reconciliation of work and family life (Boeckmann et al., 2015; Brilli et al., 2016) and reduce the relative price of childcare, therefore increasing the relative returns from labour market work (Jaumotte, 2003; Pettit and Hook, 2005). Comparing France and Germany, Lauer and Weber (2003) suggest that its early development of childcare services allowed France to have higher labour market participation and fertility compared to Germany. Similarly, studies on the Netherlands (Euwals et al., 2011) and Austria (Neuwirth, 2007) find a positive correlation between the labourmarket participation of mothers and the availability of childcare services. Very little comparative historical data on childcare and pre-primary education are available (Bahle, 2009), and the existing evidence suggests that countries have differed in the development of childcare services (see Table A1 in the Online Appendix). Cross-nationally, until the mid-1980s, public services targeted at children up to three years old were very limited, except in Scandinavian countries such as Denmark and, to a lesser extent, Sweden. In Belgium and France around $20 \%$ of children aged 0-2 years have accessed public childcare since the 1990s. While a recent childcare expansion has occurred in the Netherlands, it remains very limited in Greece, Italy, Spain, Austria and Germany.

\section{Pension systems}

Several features of national pension systems can mediate the long-term effects of work interruptions for childbearing and childrearing (Bonoli, 2003; Esping-Andersen, 1999; Hinrichs, 2000). One of these is the number of working years required for pension entitlement. If fairly low numbers of insured years, or a low retirement age, are required to access fully covered pensions, the long-lasting effects of work interruptions might be mitigated. Similarly, the availability and generosity of minimum pensions represent a form of income 
support for women with fragmented working careers, while a substantial level of ordinary pensions can improve economic conditions in later life. On the other hand, developed and generous non-contributory minimum income protection schemes for older persons can compensate for a lack of (pension) income in later life.

In the last three decades, half of the countries analysed have witnessed a slight increase in women's age at retirement, with a reduction in national differences but considerable cross-national variation in women's access to pensions (Scruggs et al., 2014). ${ }^{\text {i }}$ Sweden, Denmark and the Netherlands combine a redistribution of public resources that ensures fair economic support even by minimum pensions. The female retirement age has been stable at 65 in Sweden and the Netherlands, while Denmark joined these countries in 2005 by introducing a reduction of two years. The Dutch pension system does not require a threshold of contribution years for entitlement to full pension coverage, while in the two Nordic countries this requirement gradually increased from a very generous threshold of 15 years in Denmark and 20 years in Sweden in 1980 to 40 and 30 years respectively in 2011. The key feature in these countries is a relatively high level of economic support provided by minimum income pensions compared to the regular (old age) pension. The minimum income pension guarantees between $40 \%$ and $50 \%$ of previous pay, while old age pensions, on average, provide around $50 \%$ and 65\%. ${ }^{\text {ii }}$ Additionally, since the 1990s Sweden, Denmark and the Netherlands have implemented a noncontributory universal (conditional) basic pension for income protection in old age, ensuring a generous basic allowance for all women. Indeed, in 2012, the gross values of these benefits equalled roughly half of the national average gross wage, the highest values among the countries considered here (Goedemé and Marchal, 2016).

Italy, Germany and Spain are characterised by relatively low redistribution toward minimum income schemes, with a long earnings history needed to reach the contribution years criterion. Women are entitled to retire after the age of 60 in Italy and 65 in Germany and Spain, with 40, 45 and 35 years of work respectively. Additionally, these countries show the largest differentials between retirement and minimum pensions. If old age pensions guarantee almost the entire fictive reference salary, minimum income pensions ensure only $18 \%$ in Germany and around 27\% in Italy and Spain. Similarly, the protection generated by non-contributory social pension schemes is limited, both in terms of the persons entitled, with less than $7 \%$ of the population over 65 covered, and in terms of income protection, with Italy and Germany being respectively the most and the least 
generous (in 2012, the gross values of the benefits equalled $40 \%$ and $23 \%$ of the national average gross wage respectively), with Spain in between (32\%) (Goedemé and Marchal, 2016). Greece can be included in this group, with the exception that women with fragmented working histories are supported more generously. This occurs both through minimum income pensions, with an average replacement rate of $45 \%$ in the period considered, and through social pensions, which in 2012 showed a gross benefit value equal to that of the Nordic countries (but only reaching 3\% of the older population) (Goedemé and Marchal, 2016).

Finally, France, Belgium and Austria are characterised by important entry barriers in terms of retirement age and years of contributions but provide substantial income support through minimum and retirement pensions. In France and Austria, women are entitled to pension benefits after the age of 60, with 45 and 40 years of contributions respectively. In this regard, Belgium slightly differs in that 35 years of work are sufficient to claim retirement pensions. Income support provided by minimum pensions has gradually increased in all three countries, ensuring replacement rates of $45 \%$ in France and 50\% in Belgium and Austria in 2010, just 10-15 percentage points lower than what is ensured by regular pensions (except for Austria, where the latter provide $80 \%$ of the reference salary). In France and Belgium social pensions provide moderate protection (between $35 \%$ and $40 \%$ of the national average gross wage in 2012) to a limited share of the older population (around 5\% in the period considered), whereas in Austria special provisions for older people either do not exist or are regionalised (Goedemé and Marchal, 2016).

\section{Cross-national expectations}

The moderating role of the welfare state in the association between absence from work due to childbirth and retirement income is expected to derive from the combination of two schemes: work-family reconciliation policies (maternity leave plus childcare) and pension schemes. For analytical purposes, we group the countries analysed into four clusters according to the mix of policies implemented during the period of interest (see Table A2 in the Online Appendix for a summary).

In Nordic countries, the availability of childcare services and well-remunerated maternity leave favours the continuity of mothers' working careers. Moreover, the pension system provides a wide exit door to full pension coverage and a generous safety net through minimum and basic pensions. A similar combination also characterises the Netherlands, although it is marked by a slower development of childcare services. In these 
countries, mothers are highly supported in their working careers and pension policies guarantee generous income support in the case of fragmented working paths.

The second group of countries contains France and Belgium, where mothers historically rely on public childcare services (Belgium) and generous maternity leave (France). In contrast, despite substantial income support in both minimum and retirement pensions, high entry barriers in terms of years of contributions penalise women with fragmented working careers, and social pension schemes only protect a tiny share of older women.

Austria and Germany, the third group, are characterised by a marked orientation toward monetary solutions for work-family reconciliation. Despite the early development of generous maternity leave, the availability of public childcare is low. However, potential long-term negative effects on income can be mitigated by a redistributive orientation toward minimum pensions, especially in Austria, but only for women entitled to a retirement pension since, in both countries, the social pension plays a limited role.

Finally, in Italy, Spain and Greece public childcare services are underdeveloped and mothers rely on long parental leave. The pension systems are mainly tailored to fully protect 'regular' careers with very high replacement rates that require a long earnings history. Minimum income and social pensions are marginal and, with the only exception of Greece, scant.

In the light of these considerations, the ten countries can be placed on a pseudo-continuum where the Scandinavian countries and the Netherlands offer the best welfare package for mothers, followed by France and Belgium, and by Austria and Germany. The southern European countries offer the worst protection. Therefore, our second hypothesis is that the negative association between work interruptions and retirement income will be the smallest in Sweden, Denmark and the Netherlands, followed by the francophone and continental countries, and will be the greatest in Italy, Spain and Greece $(\mathrm{H} 2)$.

\section{Methodology}

Our analysis is based on data from the Survey on Health, Ageing and Retirement in Europe (SHARE, release 6.0.0.), a cross-national longitudinal dataset containing information about the present and past lives of ageing adults. SHARE is a panel data set surveyed biannually from 2004-2005 (wave 1) to 2014-2015 (wave 6). Wave 3 (SHARELIFE) is retrospective and allows individual employment and childbearing histories to be 
reconstructed. The population of interest consists of mothers aged 60 and above who were out of the workforce at the time of the interview and who participated in the retrospective wave and in at least one of the other waves (with the exclusion of wave 1, where, unlike the subsequent waves, data on income were collected as gross, thus raising comparability issues). When mothers participated in more than one wave, we selected the most recent observation to avoid duplicates.

Ten western European countries belonging to the European Union were selected: Austria, Belgium, Denmark, France, Germany, ${ }^{\text {iii }}$ Greece, Italy, the Netherlands, Spain and Sweden. The choice of countries was guided by both data availability and theoretical motivations. Altogether, fourteen ${ }^{\mathrm{iv}}$ countries participated in wave 3. Poland and the Czech Republic were excluded from our study in order to apply a most similar systems design focusing on western European countries belonging to the European Union. Switzerland is also extraEU and is historically characterised by considerable within-nation variation in terms of policies, as the cantons maintain substantial control over the implementation of policy areas such as social assistance, family policy, social services and education (Armingeon et al., 2004). Not being in a position to control for such withincountry variation, the country was excluded from the study. Finally, Ireland only participated in waves 2 and 3 , and so the number of observations was too small to provide reliable estimates ( $N=\sim 300)$. Altogether, after list-wise deletion of a negligible number of missing cases (1.2\%) the sample consisted of 8,168 mothers, among whom 3,894 were in a partnership.

The first dependent variable was mothers' absolute retirement income. This variable was calculated using the net annual income from public, occupational and private pensions ${ }^{\mathrm{v}}$ provided in the imputation models of each round of SHARE and taking the average of the different imputed values. ${ }^{\text {vi }}$ The values for retirement income were all provided in euros and corrected for purchasing power parity. ${ }^{\mathrm{vii}}$ A natural logarithm transformation was applied to the variable, with values of zero replaced with the minimum retirement income found in the sample for each country. ${ }^{\text {viii }}$

The second dependent variable measured differences in retirement income between mothers and their partners. The variable - built using the same income components described above - represented the mother's share of the couple's total retirement income of the couple, which complemented to $100 \%$ considering her partner's retirement income. This variable allowed for a more inclusive analysis of mothers' long-term 
penalties, highlighting the role of family and pension policies in diminishing between-gender income inequalities in later life.

The main independent variable measured the number of years mothers spent out of the labour market after the birth of their first child. The variable ranged from 0 , indicating no formal interruption from the job they held before the birth, to 33 , the longest job interruption found in the data. The sample also comprised mothers who never returned to work after the birth of the first child. These observations were top-coded at 33. Finally, mothers who were never employed throughout the life course were assigned code 34 . As robustness checks, the analyses were run i) excluding these mothers from the analyses and ii) introducing a dummy variable to differentiate them from the rest. In both cases the results were the same as in the main model.

The multivariate models controlled for the mothers' age, its square, her level of education (low as reference: primary education or lower; medium: lower and upper secondary; high: post-secondary and above), how many years the mother worked before having the child, whether the mother was ever employed (yes as reference category), the number of children she had (one as reference vs. two, three, four and above) and the decade of birth of the first child (prior to 1961 as reference; from 1961 to 1970; after 1970). We reconstructed the mother's partnership history to control for whether she experienced a change in partner after the birth of the first child (not having changed partner as reference category as opposed to having changed partner or being a single mother at the time of the birth). When focusing on mothers' relative retirement incomes, we controlled for the partner's level of education (low as reference, medium and high) and employment status (retired as reference; employed; other not employed).

The historical nature of the dataset made it challenging to construct an indicator of mothers' work experiences preceding and following maternity leave. As Möhring (2017) notes, although occupational status represents a critical element in the analysis of income inequality in later life, SHARELIFE does not allow a precise measure of this factor to be constructed. Hence, our analyses were limited in this respect as we could only focus on the length of the working career. Summary statistics for the pooled sample and by country are presented in Tables A3 and A4 in the Online Appendix.

Standard OLS models were used for both absolute and relative retirement income. All the models included country fixed effects that were interacted with the number of years mothers spent out of the labour market after the birth of their first child. Due to limitations of space, we report the main coefficients of interest in Table 1, 
while the full models are reported in Tables A5 and A6 in the Online Appendix (Models 1 and 2 for absolute income and Models 3 and 4 for relative income). To provide a straightforward interpretation of the results, Figures 3 and 4 report the predicted values of absolute and relative retirement income along with $95 \%$ confidence intervals.

\section{Results}

The data reflected well-known cross-national differences in women's income. Figure 1 shows that mothers in southern Europe had the lowest levels of absolute earned income, whereas mothers in northern and some continental countries did considerably better. Mothers' relative retirement income was below the ideal line of 0.5 everywhere but was closest to equality in Denmark (0.46) and Sweden (0.43), and particularly low in Greece (0.22) and Spain (0.15). Figure 1 also provides a preliminary assessment of the negative relationship between maternal absolute and relative retirement income and years out of work after childbirth: at the aggregate level, mothers had lower incomes in countries where, on average, they abstained longer from the labour market (e.g. Spain and Greece), compared to countries where work interruptions were shorter (e.g. Sweden and Denmark). To better understand this relationship, Figure 2 reports kernel density plots showing the distribution of mothers' time out of work after the first childbirth in each country. The percentages of mothers who never returned to the labour market or were never employed in each country are also reported in the graph. The majority of mothers in southern Europe (between $50 \%$ and $63 \%$ ) were not in the labour market after having their first child. The value was also high in the Netherlands (44\%) and the other continental and francophone countries. In contrast, Denmark and Sweden presented a more limited incidence of this phenomenon. Additionally, the graphs indicate that in almost all countries the majority of mothers who remained in the labour market returned to work within five years of the birth of their first child, while only a minority experienced longer breaks. The Netherlands and Spain deviated from this pattern, showing a somewhat slower return.

\section{[Figure 1 and Figure 2 here]}

Moving to the multivariate analyses ${ }^{\mathrm{ix}}$ (Table 1 ), Model 1 brought support for hypothesis 1: across the countries, work absence was negatively associated with retirement income $(\beta=-0.021, \mathrm{p} \leq 0.001)$. The country 
fixed effects were large and statistically significant, confirming the descriptive evidence of baseline differences in mothers' retirement income.

[Table 1 here]

In Model 2, the main term for length of job interruption remained substantially the same and statistically significant $(\beta=-0.022, \mathrm{p} \leq 0.001)$. The variation in the interaction terms with the country dummies suggested cross-national differences in the relationship between years of absence from the labour market and mothers' retirement incomes. Figure 3 reports the predicted values of absolute retirement income by country and years of absence from the labour market in different panels according to the theoretical grouping. The predictions were mean adjusted on all the covariates. Figure 3 shows a decline in retirement income as the length of the absence from the labour market increased in all the countries except Sweden and the Netherlands, where the slopes remained substantially flat, and Denmark, where the decline was not statistically significant. Substantial declines in retirement income were observed in the southern European countries and in Belgium and France. In contrast, the negative gradient of the slope was less pronounced in Germany and Austria.

As for relative retirement income, a significant and negative coefficient for years of absence from the labour market was found (Model 3, $\beta=-0.005, \mathrm{p} \leq 0.001$ ). Once the interaction terms were included, the main term for years of absence remained nearly identical (Model $4, \beta=-0.006, p \leq 0.001$ ). Figure 4 reports the meanadjusted predicted values of relative retirement income by country and length of career interruption. The figure shows that a prolonged absence from the workforce corresponded to considerably lower retirement income compared to the partner in all three southern European countries, and also in France and Belgium. Substantial declines were also observed in Germany and Austria, while the slopes were basically flat in Sweden, Denmark and the Netherlands.

[Figure 3 and Figure 4 here]

\section{Discussion}

This article presents a novel contribution by studying whether the absence of mothers from the labour market after the birth of their first child is associated with their absolute and relative retirement incomes in a comparative European perspective. The study makes three contributions to the literature. First, by looking at mothers aged 60 and above the research moves beyond previous studies that focus on the short- and medium- 
term effects of job interruptions on income (Budig and Hodges, 2010; Sefton et al., 2011). By focusing on a demographic that is largely overlooked in the literature on motherhood penalties, the article not only sheds light on the possible long-term implications of work interruptions but also suggests that to understand inequalities among older segments of the population it is imperative to look at the potential roots of these inequalities. Since older women are a social group at high risk of poverty, understanding how family and career histories interact in determining mothers' incomes in old age is crucial in the development of appropriate policy tools (Peeters and De Tavernier, 2015). In this respect, a fruitful avenue for future research is to compare the retirement income of mothers with varying lengths of absence from work and of childless women. Considering that the incidence of childlessness is on the rise in western countries (OECD, 2019) it is plausible to foresee increases in social inequalities between mothers and non-mothers. Therefore, a broad assessment of policy interventions targeted at different subgroups becomes imperative.

Second, the article's comparative approach focused on ten countries belonging to different welfare and gender regimes (Esping-Andersen, 1990; Korpi et al. 2013) offers a more comprehensive picture compared to previous single-country studies (Ginn, 2003; Kahn et al., 2014; Phipps et al., 2001). Examination of three different welfare areas covering over forty years in ten countries proves useful to identify 'best policy practices' that can be fruitfully applied in other countries, in particular those with a liberal-residual welfare regime such as the UK and Ireland, which provide little support to working mothers. Third, by looking at both absolute and relative retirement incomes, this article explores two different aspects of income inequality: i) the focus on absolute retirement income allows a within-gender analysis of the risks that older mothers face in terms of income inequality; and ii) looking at relative retirement income sheds light on the balance of earnings and the dynamics of power within a subpopulation that is seldom considered in studies of within-household gender inequalities.

The findings map well against the first hypothesis: staying many years out of the work force after the birth of the first child is negatively associated with mothers' absolute and relative retirement incomes. Crossnational differences in the results bring partial support to the second hypothesis: no negative association appears in Sweden and Denmark, where maternity and parental leave allowances have historically been more generous (Gauthier, 2011), childcare services are developed and a universalistic pension system offers economic support even to workers with highly fragmented work trajectories (Esping-Andersen, 1990). The 
Netherlands, characterised by a delayed development of childcare, appears to have followed the road of the two northern European countries, showing limited negative long-term effects of maternity-related work interruptions. Job interruptions for childbirth are associated with greater income reductions in southern and continental countries, but also in Belgium and France, which appear to offer some protection to working mothers. Hence, the second hypothesis is only partially confirmed. This suggests that a generosity of the pension system, as in the case of the Netherlands and to a smaller extent Germany and Austria, can in part offset shortages in family and reconciliation policies. In contrast, high entry barriers to the pension system and generous support for regular careers result in higher income inequalities in later life, as in the case of the three southern European countries.

To shed further light on cross-national differences in the results, we briefly discuss how labour market policies (LMP), in particular part-time employment and expenditure on (active) LMPs, can significantly reduce mothers' absences from the workforce. OECD data show a very large use of part-time employment in the Netherlands in all the years considered (between $50 \%$ and $60 \%$ of women were employed). In contrast, until the mid-1990s around a third of employed women in the other countries had part-time employment, a proportion that slightly rose in the following years to about only $35 \%$ in Germany, Belgium, Italy and Austria (see Figure A1 in the Online Appendix). As far as expenditure is concerned, Denmark and the Netherlands are historically characterised by spending very high shares of GDP on LMPs, whereas Sweden stands out for its orientation toward active, rather than passive, polices (see Figure A2). The southern countries, in contrast, present minimal expenditure on LMPs. Spending has grown over the decades in France, Germany and Austria, while it remains somewhat stable in Belgium, where only a minor share of the high spending on LMPs has been directed to active policies.

LMP indicators seem to suggest two different strategies to limit mothers' income inequality in later life. The strategy in the Nordic countries was to help women and mothers enter and stay in the labour market with policy packages offering high childcare coverage and generous maternity leave on the one hand and high expenditure on (active) LMPs on the other. Moreover, a generous pension system acted as a further safety net to support women with fragmented working careers. In contrast, the Netherlands reached a similar result through an extensive use of part-time work, thanks to which a large share of women entered the labour market but also easily opted out for medium-long periods. Here, welfare and LMPs, instead of directly supporting 
mothers in their working careers, indirectly encouraged a passive form of reconciliation between work and family, leaving the pension system to compensate for income inequality in later life.

\section{Conclusions}

To summarise, the article shows that the longer a mother abstains from work after the birth of her first child, the lower her absolute or relative retirement income is. However, mothers in Denmark, Sweden and the Netherlands are largely unaffected by the length of their absence from the workforce, in both absolute and relative terms. These results support the hypothesis that the negative association between the length of the absence from the labour market and retirement income is negligible in countries where the welfare state effectively decommodifies its citizens.

Two main considerations on these results can help to push forward the theoretical debate regarding the relation between national institutional features and gender inequalities. First, the overall comparative results highlight a need to tackle long-term motherhood penalties through a dual decommodification that a) directly eases the care load connected to child-rearing through extensive childcare support and b) indirectly supports non-standard career pathways through the pension system together with generous non-contributory measures. Second, the comparison between the Scandinavian countries and the Netherlands provides practical examples of combining the two approaches: mostly supporting women to be independent in both economic and childcare terms in Scandinavia and mostly economically compensating the family role of mothers in the Netherlands. The two pathways result in different degrees of decommodification and implications for the welfare system, both of which should be accounted for when deciding which to adopt in other contexts.

Three limitations of the study must be acknowledged. First, the retrospective data cover a very long period and it could be argued that they are liable to recall bias. However, ex-post analysis checking for internal consistency of SHARELIFE data indicates that scepticism about their quality is not warranted (Havari and Mazzonna, 2011). Second, the results are confined to a sub-sample of the countries available in SHARE. Although the selected countries cover different welfare and gender systems, the findings are not generalisable to a different pool of countries. Nevertheless, they suggest that institutional characteristics and life course events are intertwined key factors in an analysis of gender inequalities, especially as far as the cumulative temporal dimension is concerned. Third, due to data limitations, we cannot fully control for mothers' past 
occupational status and whether its evolution over the life course has a mitigating or strengthening role in the long-term effect of maternity-related work interruptions on income. Future research could fruitfully address this limitation, given that occupational status might very well play a role in this respect.

To conclude, it is argued that the long-term effects of absence from the labour market after childbirth on mothers' retirement incomes should not be considered only as a product of individual historical legacies but should be included in a broader reasoning about present and future challenges posed to welfare states. Population ageing, decreased fertility, shrinking family sizes, increasing retirement ages and decreasing pension incomes are threatening the social sustainability of welfare systems as they are known today (Zaidi et al., 2010). Considering that mothers are both 'passive' beneficiaries of social benefits and 'active' pivotal elements in intergenerational families, ensuring adequate economic support for older mothers in later life through a correct calibration of family, labour market and pension policies is a task that welfare states cannot avoid. 


\section{Endnotes}

${ }^{i}$ The data are derived from the Comparative Welfare Entitlements Dataset (CWED) and refer only to mandatory public programmes (Scruggs et al., 2014).

${ }^{\text {ii }}$ Replacement rates are calculated for a fictive average production worker in manufacturing who is 40 years old, living alone with no children or other dependents and working for the 20 years preceding the benefit period (Scruggs et al., 2014).

iii Because of a lack of historical institutional data on pension systems and work-family reconciliation policies, mothers who resided in the DDR before 1989 were excluded.

iv The United Kingdom has never been included in the SHARE survey since it has its own (English) Longitudinal Study of Ageing (ELSA).

${ }^{v}$ The public pensions considered are: old age pension; old age supplementary pension; early retirement/pre-retirement pension; main survivor pension from spouse/partner; secondary survivor pension from spouse/partner; and war pension. The occupational and private pensions are: old age pension from the last occupation; old age pension from a second and a third occupation; early retirement pension; survivor pension from spouse/partner's occupation; occupational disability or invalidity insurance.

${ }^{\text {vi }}$ Each round of SHARE provides an imputation module in which the missing values of a limited number of variables (among which are those connected to individual and household sources of income) are replaced employing five different values obtained through as many imputation techniques, leaving the non-missing values unchanged (BörschSupan et al., 2013).

vii The SHARE survey provides nominal exchange rates and exchange rates for each survey year, and PPP-adjustment, to transform financial amounts into real ones based on prices in Germany in 2005.

viii We adopt this approach following Möhring (2018). The replacement of zero values is necessary to avoid losing subjects whose retirement income is equal to zero when the variable is logged. The extent of the replacement varies considerably across countries, ranging from a minimum of $6 \%$ in Sweden to a maximum of $45 \%$ in Spain (see Table A3 in the Online Appendix). The alternative strategy of replacing zeros with a very small number yields consistent results. ${ }^{i x}$ As for the controls, a curvilinear association for age emerged along with a positive and significant coefficient for the more highly educated category. The coefficient for medium educated mothers was also positive but smaller and not statistically significant. No association emerged between the number of years worked prior to the birth of the child and retirement income. Mothers who were never employed had lower retirement incomes and each additional child led to a decrease in retirement income, although the association was only statistically significant for the third child.

\section{Acknowledgements}

The support of the JPI MYBL 2016 - Project "Care and Income Redistributive Cycles in the Lives of the Europeans" (CIRCLE) - is gratefully acknowledged.

The authors would also like to thank the anonymous reviewers for their careful reading of the manuscript and the multiple suggestions and insightful comments. The authors contributed equally to this manuscript and are listed alphabetically. 


\section{Reference list}

Armingeon K, Bertozzi F and Bonoli G (2004) Swiss worlds of welfare. West European Politics 27 (1): 20 44.

Bahle T (2009) Public childcare in Europe: Historical trajectories and new directions. In: Scheiwe K, Harry W (eds) Child Care and Preschool Development in Europe Institutional Perspectives. Palgrave MacMillan, 23-42.

Baum CL (2002) The effect of work interruptions on women's wages. Labour 16(1): 1-37.

Boeckmann I, Misra J and Budig MJ (2015) Cultural and institutional factors shaping mothers' employment and working hours in postindustrial countries. Social Forces 93(4): 1301-33.

Bonoli G (2003) Two worlds of pension reform in Western Europe. Comparative Politics 35(4): 399-416.

Börsch-Supan A, Brandt M, Hunkler C, Kneip T, Korbmacher J, Malter F et al. (2013): Data Resource Profile: The Survey of Health, Ageing and Retirement in Europe (SHARE). International Journal of Epidemiology 42 (4): 992-1001.

Brilli Y, Del Boca D and Pronzato C (2016) Does child care availability play a role in maternal employment and children's development? Evidence from Italy. Review of Economics of the Household 14(1): 27-51.

Budig MJ, Hodges MJ (2010) Differences in disadvantage variation in the motherhood penalty across white women's earnings distribution. American Sociological Review 75(5): 705-28.

Burkevica Ilze, Humbert AL, Oetke N and Paats M (2015). Gender gap in pensions in the EU European Institute for Gender Equality.

Dotti Sani GM (2015). Within-couple inequality in earnings and the relative motherhood penalty. A crossnational study of European countries. European Sociological Review 31(6): 667-682.

Ejrnæs M and Kunze A (2013). Work and wage dynamics around childbirth. Scandinavian Journal of Economics 115(3): 856-77.

Esping-Andersen G (1990). The Three Worlds of Welfare Capitalism. Princeton: Princeton University Press.

Esping-Andersen G (1999) Social Foundations of Postindustrial Economies. Oxford: Oxford University Press.

Esping-Andersen G (2000) Multi-dimensional decommodification: A reply to Graham Room, Policy \& Politics, 28(3): 353-9.

Euwals R, Knoef M and Van Vuuren D (2011) The trend in female labour force participation: What can be expected for the future? Empirical Economics 40(3): 729-53.

Fasang AE, Aisenbrey S and Schömann K (2013) Women's retirement income in Germany and Britain. European Sociological Review 29(5): 968-80.

Folbre N, Shaw L and Stark A (2007) Warm Hands in Cold Age: Gender and Aging. Routledge.

Gangl M and Ziefle A (2009) Motherhood, labor force behavior, and women's careers: An empirical assessment of the wage penalty for motherhood in Britain, Germany, and the United States. Demography 46(2): 341-369. 
Gauthier AH (2011) Comparative Family Policy Database, Version 3 [computer File]. Netherlands Interdisciplinary Demographic Institute and Max Planck Institute for Demographic Research (distributors). Retrieved from: www.demogr.mpg.de.

Ginn J (2003) Parenthood, partnership status and pensions: Cohort differences among women. Sociology 37(3): 493-510.

Goedemé T and Marchal S (2016) Exploring a blind spot in comparative pension reform research: Long-term trends in non-contributory pensions in Europe. International Journal of Social Welfare 25: 161-75.

Gornick JC, Sierminska E and Smeeding TM (2009) The income and wealth packages of older women in cross-national perspective. The Journals of Gerontology Series B: Psychological Sciences and Social Sciences 64(3): 402-14.

Havari E and Mazzonna F (2011) Can we trust older people's statements on their childhood circumstances? Evidence from Sharelife. SHARE, Survey of Health, Ageing and Retirement in Europe. Working Paper Series 05-2011. http://ssrn.com/abstract=2004299.

Hinrichs K (2000) Elephants on the move. Patterns of public pension reform in OECD countries. European Review 8(03): 353-78.

Jaumotte F (2003) Female labour force participation: Past trends and main determinants in OECD Countries. OECD ECO/WKP(2003) 30: 2-66.

Jefferson T (2009) Women and retirement pensions: A research review. Feminist Economics 15(4): 115-45.

Kahn JR, Garcia-Manglano J and Bianchi SM (2014) The motherhood penalty at midlife: Long-term effects of children on women's careers. Journal of Marriage and Family 76(1): 56-72.

Killewald A (2013) A Reconsideration of the fatherhood premium: Marriage, coresidence, biology, and fathers' wages. American Sociological Review 78(1): 96-116.

Klesment M and Van Bavel J (2017). The reversal of the gender gap in education, motherhood, and women as main earners in Europe. European Sociological Review 33(3): 465-481.

Korpi W, Ferrarini T and Englund S (2013). Women's opportunities under different family policy constellations: Gender, class, and inequality tradeoffs in western countries re-examined. Social Politics: International Studies in Gender, State \& Society 20(1): 1-40.

Lalive R and Zweimüller J (2009) How does parental leave affect fertility and return to work? Evidence from two natural experiments. The Quarterly Journal of Economics 124(3): 1363-1402.

Lauer C and Weber AM (2003) Employment of Mothers after Childbirth: A French-German Comparison. Discussion Paper 03-05. ZEW. Centre for European Economic Research.

Lundberg S and Rose E (2000) Parenthood and the earnings of married men and women. Labour Economics 7(6): 689-710.

Mincer J and Ofek H (1982) Interrupted work careers: Depreciation and restoration of human capital. Journal of Human Resources 7(1): 3-24.

Möhring K (2018) Is there a motherhood penalty in retirement income in Europe? The Role of lifecourse and institutional characteristics. Ageing \& Society, 30(12): 2560-2589.

Neuwirth N (2007) The determinants of activities within the family. Austrian Institute for Family Studies 59. 
OECD (2019) OECD Family Database. SF2.5 Childlessness. Table SF2.5A Childless women at age 40-44a, mid-1990s and 2010 (or latest available year). Accessed November 2019.

Peeters H and De Tavernier W (2015) Lifecourses, pensions and poverty among elderly women in Belgium: Interactions between family history, work history and pension regulations. Ageing \& Society 35(6): 117199.

Pettit B and Hook JL (2005) The structure of women's employment in comparative perspective. Social Forces 84(2): 779-801.

Phipps S, Burton P and Lethbridge L (2001) In and out of the labour market: Long-term income consequences of child-related interruptions to women's paid work. Canadian Journal of Economics 34(2): 411-29.

Pintelon O (2012) Welfare state decommodification: Concepts, operationalizations and long-term trends. Working Papers 1210, Herman Deleeck Centre for Social Policy, University of Antwerp.

Scruggs L, Detlef J and Kuitto K (2014) Comparative welfare entitlements dataset 2. Version 2014-03. University of Connecticut \& University of Greifswald.

Sefton T, Evandrou M, Falkingham J and Vlachantoni A (2011) The relationship between women's work histories and incomes in later life in the UK, US and West Germany. Journal of European Social Policy 21(1): 20-36.

Sigle-Rushton W and Waldfogel J (2007) Motherhood and women's earnings in Anglo-American, continental European, and Nordic countries. Feminist Economics 13(2): 55-91.

Stier H and Mandel H (2009) Inequality in the family: The institutional aspects of women's earning contribution. Social Science Research 38: 594-608.

Tietze W and Cryer D (1999) Current trends in European early childcare and education, ANNALS, AAPSS, 563: 175-93.

Treas J and Drobnič S (2010) (Eds) Dividing the Domestic. Men, Women, and Household Work in CrossNational Perspective. Stanford, Stanford University Press.

Uunk W, Kalmijn M and Muffels R (2005) The impact of young children on women's labour supply: A reassessment of institutional effects in Europe. Acta Sociologica 48(1): 41-62.

Zaidi A, Gasior K and Sidorenko A (2010) Intergenerational Solidarity: Policy Challenges and Societal Responses. Policy Brief 7/10. Vienna: European Centre. 
Giulia Maria Dotti Sani is Assistant Professor in the Department of Social and Political Sciences at the University of Milano Statale. She holds a PhD in Sociology and Social Research. Her main research areas are sociology of the family, female employment and social stratification. Her methodological skills include time budget analysis, multilevel and panel modelling. Her works appear in international peer reviewed journals such as the European Sociological Review, the Journal of Marriage and Family, Sex Roles and the European Journal of Political Research.

Matteo Luppi is Post-doc Fellow at the National Institute of Public Policy Analysis (INAPP) in Rome. He holds a European PhD in Socio-Economic and Statistical Studies. His main research interests concern the ageing population process, with special attention to comparative studies of welfare states, elderly care and intergenerational relations and inequalities. He has extensively worked on SHARE data, focusing on poverty and gender inequalities in later life. His works appear in international peer reviewed journals such as the European Sociological Review, Current Sociology and Social Policy \& Administration. 


\section{Tables and figures}

Table 1. Results for mothers' absolute incomes (log PPP, Models 1 and 2) and relative incomes (Models 3 and 4). Standard errors in parentheses. Own elaboration on SHARE data

\begin{tabular}{|c|c|c|c|c|c|c|}
\hline & \multirow[t]{2}{*}{ Model 1} & \multicolumn{2}{|c|}{ Model 2} & \multirow[t]{2}{*}{ Model 3} & \multicolumn{2}{|c|}{ Model 4} \\
\hline & & Main terms & Interactions & & Main terms & Interactions \\
\hline Years of absence after $1^{\text {st }}$ birth & $\begin{array}{c}-0.021 * * * \\
(0.001)\end{array}$ & $\begin{array}{c}-0.022 * * * \\
(0.005)\end{array}$ & & $\begin{array}{c}-0.005 * * * \\
(0.001)\end{array}$ & $\begin{array}{c}-0.006 * * * \\
(0.001)\end{array}$ & \\
\hline Country (r.c. Austria) & & & & & & \\
\hline Germany & $\begin{array}{c}-0.475 * * * \\
(0.087)\end{array}$ & $\begin{array}{c}-0.566^{* * * *} \\
(0.114)\end{array}$ & $\begin{array}{c}0.008 \\
(0.006)\end{array}$ & $\begin{array}{l}-0.015 \\
(0.020)\end{array}$ & $\begin{array}{l}-0.035 \\
(0.027)\end{array}$ & $\begin{array}{c}0.002 \\
(0.001)\end{array}$ \\
\hline Sweden & $\begin{array}{l}-0.076 \\
(0.082)\end{array}$ & $\begin{array}{c}-0.182+ \\
(0.105)\end{array}$ & $\begin{array}{l}0.016 * \\
(0.007)\end{array}$ & $\begin{array}{l}0.065^{* *} * \\
(0.020)\end{array}$ & $\begin{array}{c}0.026 \\
(0.025)\end{array}$ & $\begin{array}{l}0.005 * * \\
(0.002)\end{array}$ \\
\hline Netherlands & $\begin{array}{c}0.101 \\
(0.082)\end{array}$ & $\begin{array}{c}-0.243 * \\
(0.119)\end{array}$ & $\begin{array}{c}0.018 * * \\
(0.006)\end{array}$ & $\begin{array}{l}0.047 * \\
(0.019)\end{array}$ & $\begin{array}{l}-0.033 \\
(0.027)\end{array}$ & $\begin{array}{c}0.005 * * * \\
(0.001)\end{array}$ \\
\hline Spain & $\begin{array}{c}-0.999 * * * \\
(0.083)\end{array}$ & $\begin{array}{c}-1.109 * * * \\
(0.129)\end{array}$ & $\begin{array}{c}0.004 \\
(0.006)\end{array}$ & $\begin{array}{c}-0.068 * * * \\
(0.020)\end{array}$ & $\begin{array}{c}-0.086 * * \\
(0.031)\end{array}$ & $\begin{array}{c}0.001 \\
(0.001)\end{array}$ \\
\hline Italy & $\begin{array}{c}-0.478 * * * \\
(0.080)\end{array}$ & $\begin{array}{c}-0.295 * * \\
(0.109)\end{array}$ & $\begin{array}{l}-0.011^{*} \\
(0.005)\end{array}$ & $\begin{array}{c}0.016 \\
(0.019)\end{array}$ & $\begin{array}{l}-0.001 \\
(0.025)\end{array}$ & $\begin{array}{c}0.001 \\
(0.001)\end{array}$ \\
\hline France & $\begin{array}{l}0.132+ \\
(0.079)\end{array}$ & $\begin{array}{l}0.245 * \\
(0.102)\end{array}$ & $\begin{array}{c}-0.010+ \\
(0.005)\end{array}$ & $\begin{array}{l}0.034+ \\
(0.019)\end{array}$ & $\begin{array}{c}0.033 \\
(0.024)\end{array}$ & $\begin{array}{c}0.000 \\
(0.001)\end{array}$ \\
\hline Denmark & $\begin{array}{c}-0.303 * * * \\
(0.081)\end{array}$ & $\begin{array}{c}-0.418 * * * \\
(0.103)\end{array}$ & $\begin{array}{l}0.015 * \\
(0.006)\end{array}$ & $\begin{array}{c}0.096 * * * \\
(0.020)\end{array}$ & $\begin{array}{l}0.049 * \\
(0.025)\end{array}$ & $\begin{array}{c}0.006 * * * \\
(0.002)\end{array}$ \\
\hline Greece & $\begin{array}{c}-0.686 * * * \\
(0.081)\end{array}$ & $\begin{array}{c}-0.701 * * * \\
(0.113)\end{array}$ & $\begin{array}{l}-0.001 \\
(0.005)\end{array}$ & $\begin{array}{l}-0.014 \\
(0.020)\end{array}$ & $\begin{array}{l}-0.002 \\
(0.027)\end{array}$ & $\begin{array}{l}-0.000 \\
(0.001)\end{array}$ \\
\hline Belgium & $\begin{array}{c}-0.594 * * * \\
(0.077)\end{array}$ & $\begin{array}{c}-0.415^{* * *} \\
(0.101)\end{array}$ & $\begin{array}{l}-0.013 * \\
(0.005)\end{array}$ & $\begin{array}{c}-0.035+ \\
(0.018)\end{array}$ & $\begin{array}{l}-0.018 \\
(0.024)\end{array}$ & $\begin{array}{l}-0.001 \\
(0.001)\end{array}$ \\
\hline $\mathrm{BIC}$ & 28250 & & & -906.879 & -905.606 & \\
\hline Log-likelihood & -14017 & & & 569.180 & 605.746 & \\
\hline Sig. & 0.000 & & & 0.000 & 0.000 & \\
\hline $\mathrm{N}$ & & 8168 & & & 3894 & \\
\hline
\end{tabular}


Figure 1 Country averages of mothers' absolute (log PPP, right-hand y-axis) and relative retirement incomes (left-hand y-axis) against country average of years out of the labour market. Own elaboration on SHARE data.

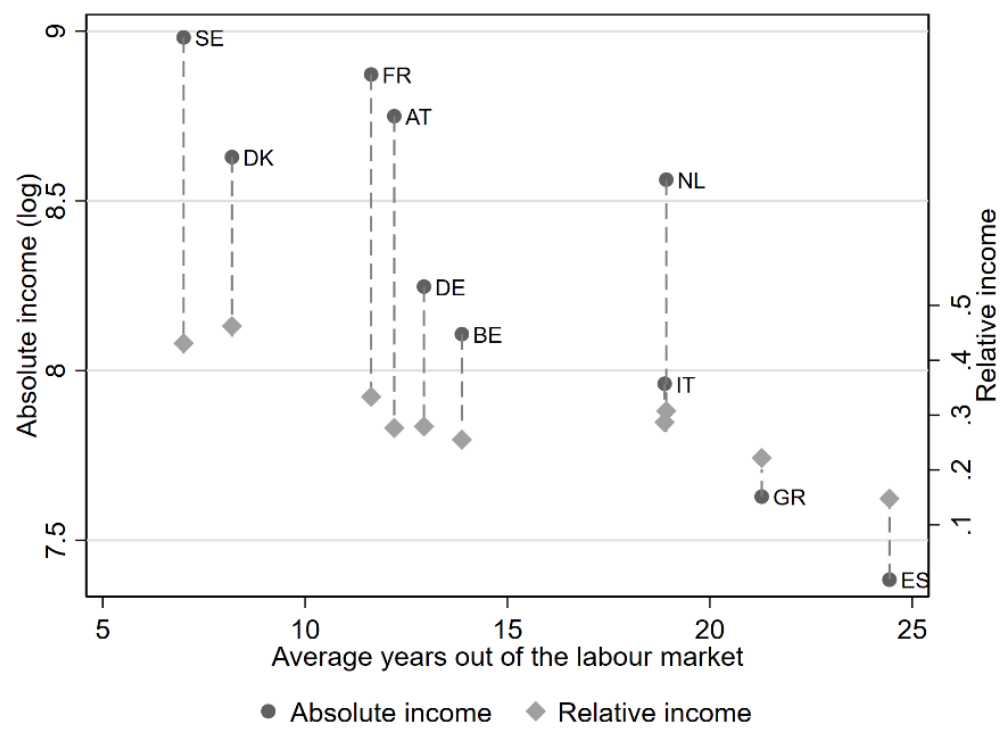


Figure 2 Distribution of years out of the labour market by country (kernel densities). Own elaboration on SHARE data.
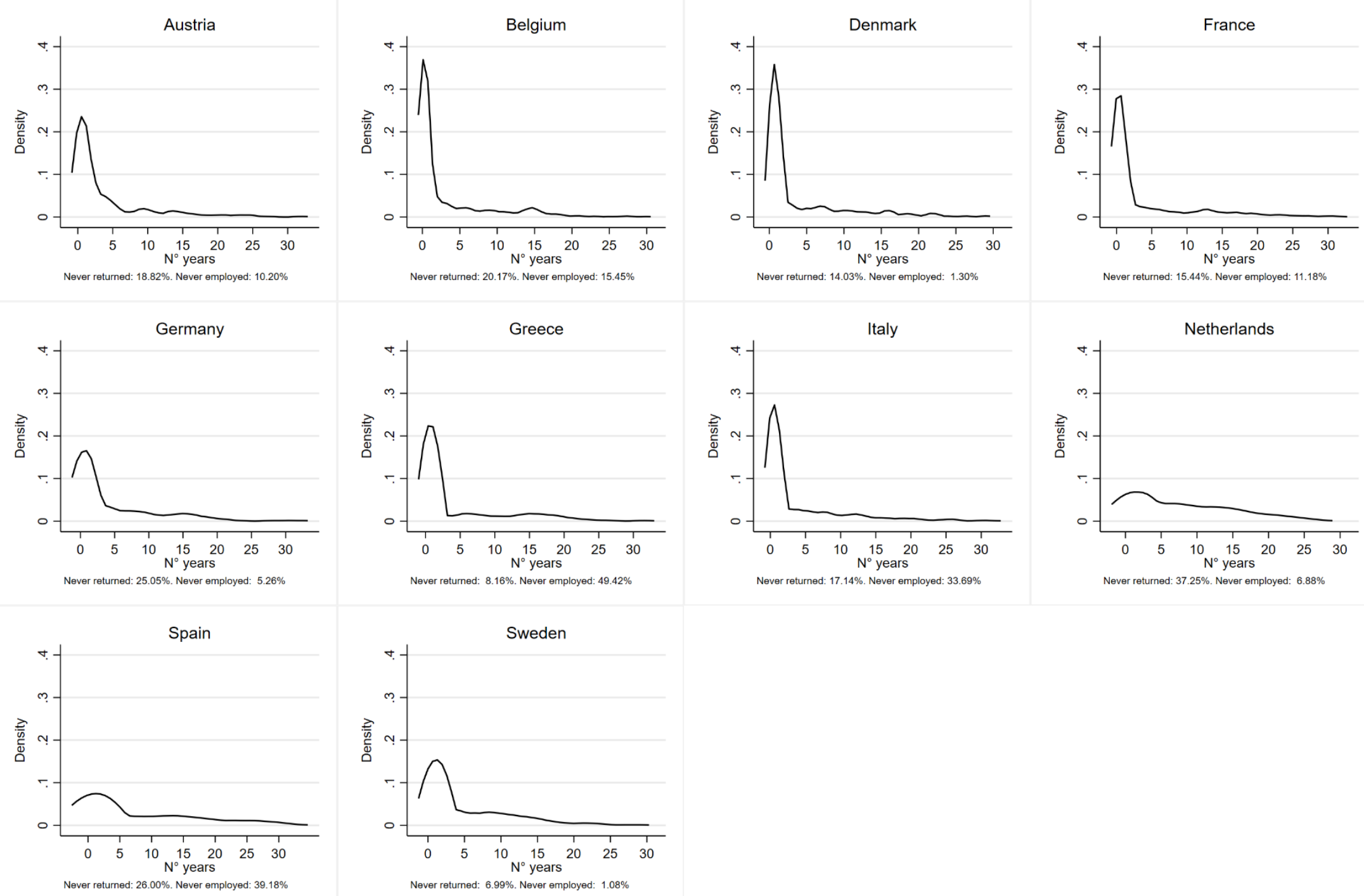
Figure 3. Predicted values of absolute retirement incomes (log PPP) derived from Model 2. Own elaboration on SHARE data.

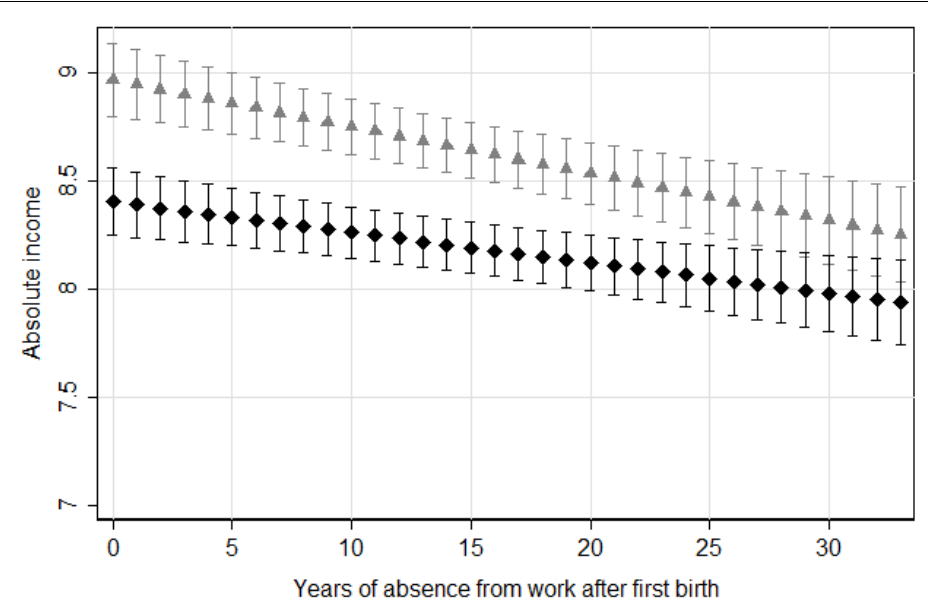

$\triangle A T$ DE

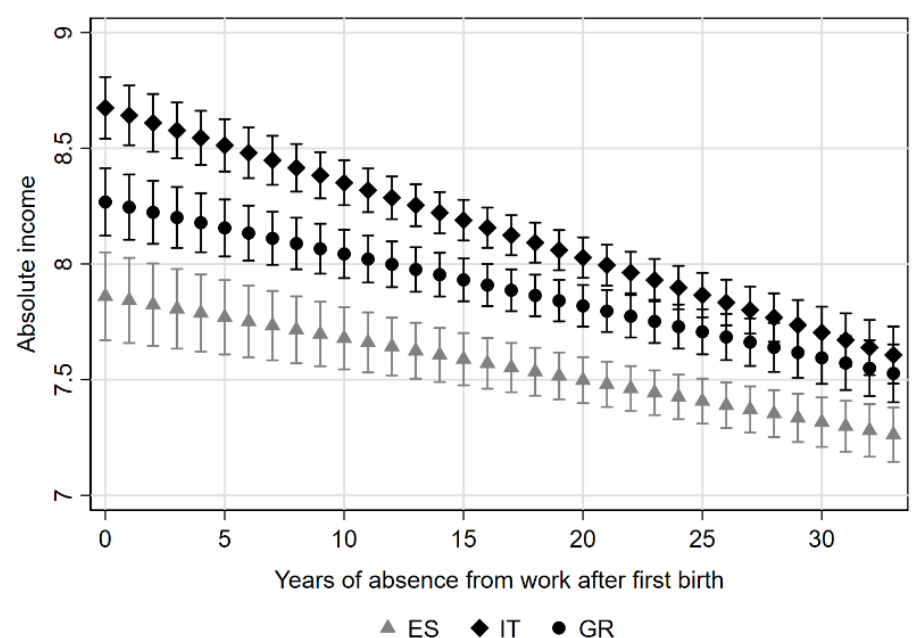

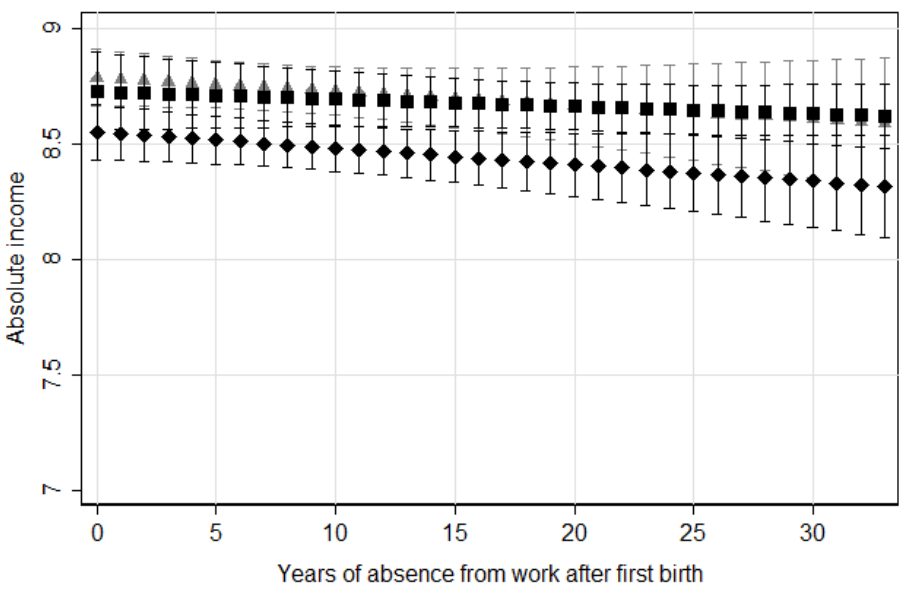

$\triangle \mathrm{SE}$ - DK - NL

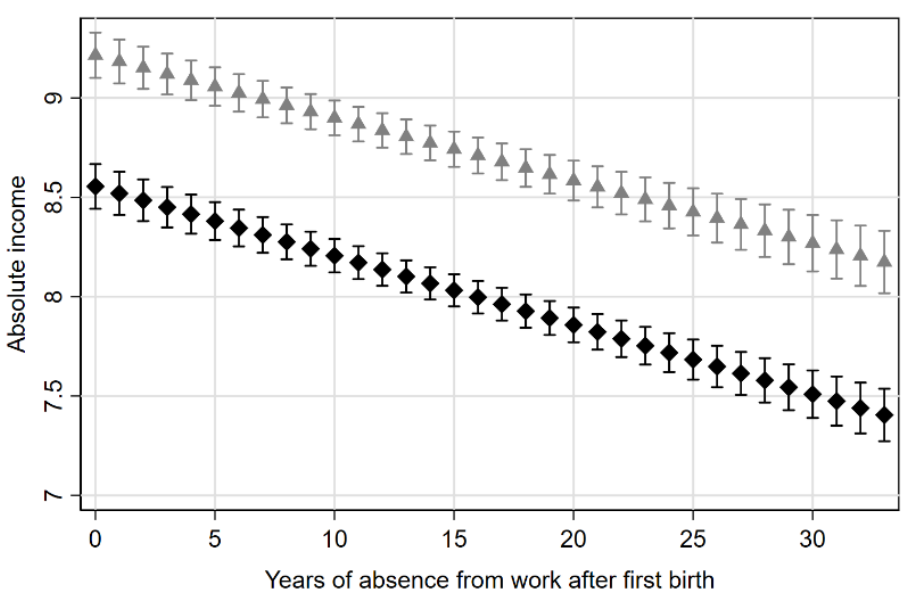

$\triangle \mathrm{FR} \bullet \mathrm{BE}$ 
Figure 4. Predicted values of relative retirement incomes derived from Model 4. Own elaboration on SHARE data.

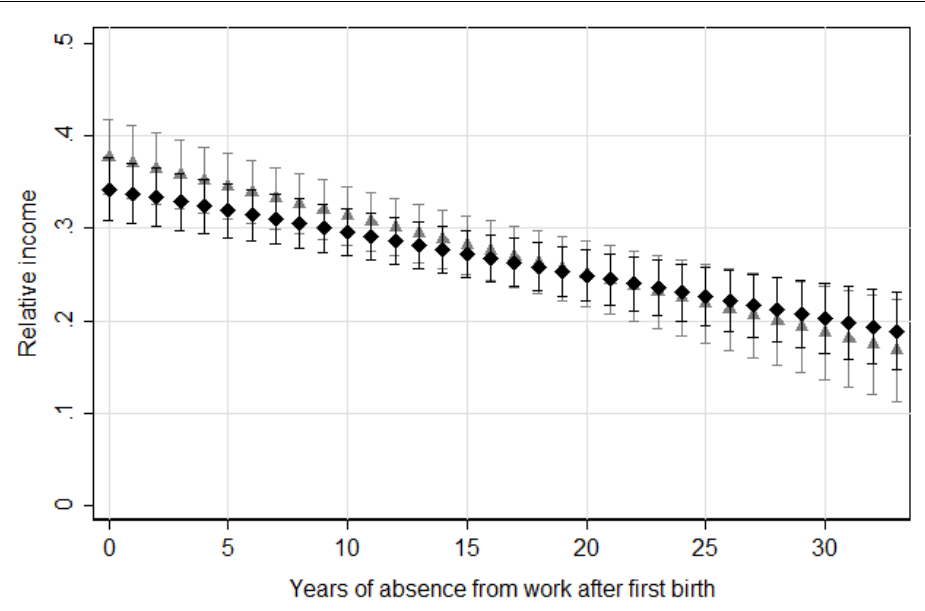

$\triangle \mathrm{AT} \bullet \mathrm{DE}$

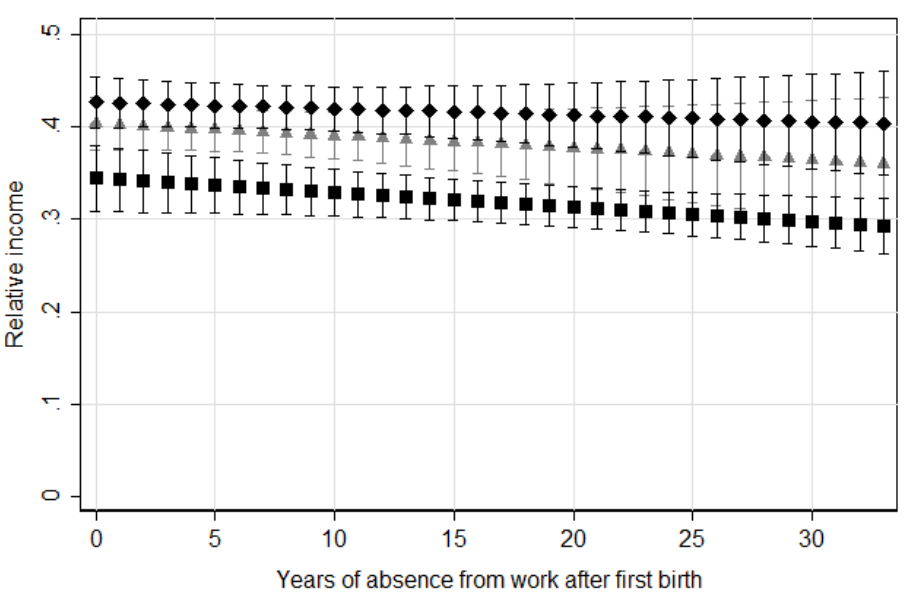

$\triangle \mathrm{SE} \bullet \mathrm{DK} \bullet \mathrm{NL}$
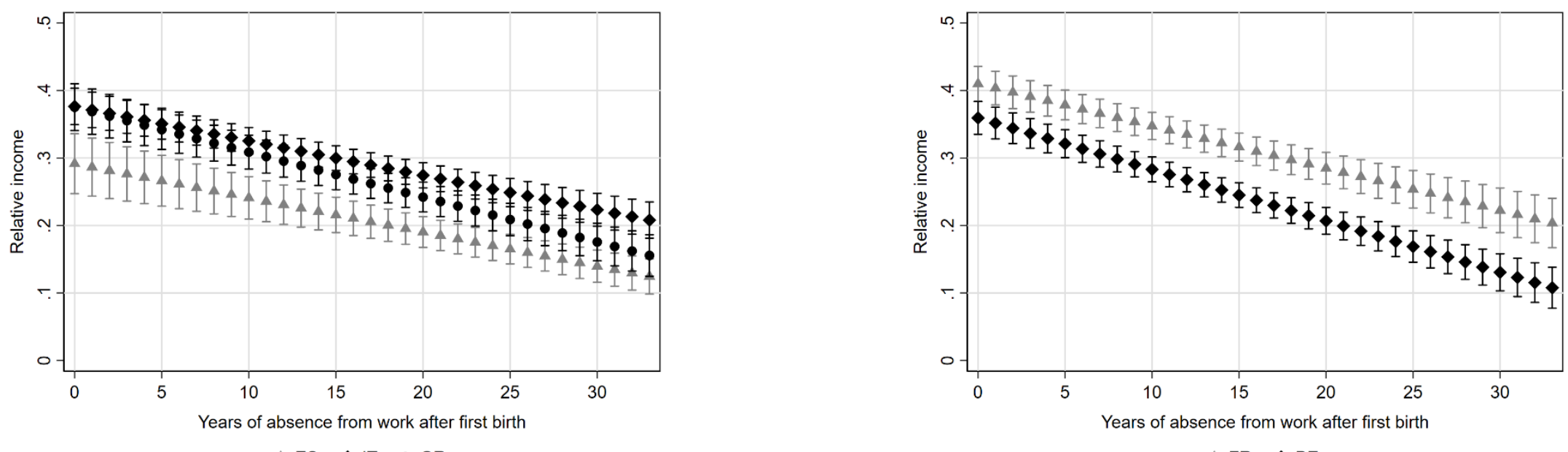

$\triangle \mathrm{FR} \bullet \mathrm{BE}$ 